\title{
Analysis of expression levels of genes involved in the nacre color of Hyriopsis cumingii shell
}

\author{
Zhi Gang Wang ${ }^{\mathrm{a}}$, Yi Yun Mei ${ }^{\mathrm{a}}$, Rong Quan Zheng ${ }^{\mathrm{a}, \mathrm{b}, \mathrm{c}, *}$, Yuan Yuan Mao ${ }^{\mathrm{a}}$, Gen Fang Zhang ${ }^{\mathrm{d}}$, \\ Rong Hui Ye ${ }^{d}$ \\ a College of Chemistry and Life Sciences, Zhejiang Normal University, Jinhua 321004 China \\ ${ }^{b}$ Key Lab of Wildlife Biotechnology and Conservation and Utilization of Zhejiang, Jinhua 321004 China \\ c Xingzhi College, Zhejiang Normal University, Jinhua 321004 China \\ d Jinhua Polylechnic, Jinhua 321004 China
}

*Corresponding author, e-mail: zhengrq@zjnu.cn

Received 27 Sep 2018

Accepted 4 Feb 2020

\begin{abstract}
Freshwater mussel Hyriopsis cumingii is ubiquitous in China and commercially valuable for freshwater pearl production. Donor pearl mussel or oyster shell nacre color considerably affects pearl color, but the molecular mechanism underlying pearl color remains unclear. Mussels with purple and white inner-shell colors were selected, and five genes related to nacreous layer color formation were identified through comparative transcriptome analysis. Real-time quantitative analysis indicated that HcTyr 1 encoding tyrosinase is involved in black pigment synthesis. HcTyr 1 expression in rear edge films was higher in the purple mussels $(p<0.05)$. The expression in the posterior and anterior mantle pallial of HcAst, which encodes shrimp erythropoietin, was higher in the purple mussels $(p<0.01)$. HcAst expression in the central membrane was also higher in the purple mussels $(p<0.05)$. The expression of $H c C y t$, which encodes cytochrome P450, was higher in the central membranes of the purple mussels than in the posterior and anterior mantle pallial and the central membranes of the white mussels $(p<0.01)$. The expression in the posterior mantle pallial of HCTDO, which encodes tryptophan oxygenase involving in ophthalmic lutein synthesis, was significantly higher in the purple mussels $(p<0.01)$. No difference in expression regularity in the outer mantle of HcUROD which encodes urine porphyrin decarboxylase participating in heme synthesis was observed among the mussels, and the expression was higher in the posterior marginal membrane than in the central membrane $(p<0.01)$. These studied genes are involved in nacre color formation in $H$. cumingii.
\end{abstract}

KEYWORDS: Hyriopsis cumingii, nacre color, gene, differential expression

\section{INTRODUCTION}

Freshwater mussel Hyriopsis cumingii is widely distributed in China and commercially valuable for freshwater pearl production. H. cumingii is a freshwater bivalve mollusk, belonging to cladocranchia, mussel family and Hyriopsis. H. cumingii's shell possesses thick chitin and is flat, broad and hard. The shell on the back rises to form a triangular sail wing, from where the name $H$. cumingii is derived. As an important freshwater mussel in China, $H$. cumingii produces pearls that account for $>98 \%$ of the world's total freshwater pearls. Pearl is a natural organic gemstone that can be used not only in medicine and cosmetics but also as an accessory. The biological characteristics of pearl have been the subject of research in bionics material science. Color is an important indicator in the evaluation of pearls because it influences their value and quality.
Pearls produced by $H$. cumingii are rich in color, which includes yellow, purple, white and red, and have different shades of color. The prices of different colored pearls are lower than those of purecolored pearls, which are more popular among consumers [1]. Similar to shell formation, pearls are produced by a biological mineralization process. The structures and compositions of pearls are consistent with shell nacre. Therefore, pearl color can be investigated by evaluating the shell nacre color.

Shell pearl layer color is mainly determined by heredity [2]. Hence, selecting genes related to pearl color is crucial. At present, few studies have focused on genes that influence pearl color formation. A previous work screened apolipoprotein genes [3]. Another study compared the coat membrane tissue of the purple and white inner-shell colors of $H$. cumingii's coat film with pearl capsule through 
transcriptome analysis [4]. The screened genes, namely, HcGIFLP1, HcGIFLP2, HcCUBDC and HcCA2, are related to pearl layer color formation. Chen [5] cloned two tyrosinase genes (HcTyr and HcTyp-1) of $H$. cumingii and conducted fluorescence quantitative expression and in situ hybridization signal detection. HcTyr is related to $H$. cumingii pearl layer color formation, and its expression in the purple mussel membrane is higher than that of the white mussel. HcTyp-1 is related to the color formation of the pearl and cuticle layers and highly expressed in the white clam mantle film. These genes are mainly involved in pigment transport and synthesis. Pearl color can be attributed to a variety of factors, and the molecular mechanism of nacre color formation must be further explored. Therefore, other genes related to pearl color must be selected and studied for the elucidation of the molecular mechanism of pearl color formation.

This study evaluated pigment-related genes. Then, five differentially expressed genes of tyrosinase including HcTyr1, were selected from the library of the central membrane transcriptome of $H$. cumingii. Other genes included astacin metalloprotease, cytochrome P450, tryptophan dioxygenase, and uroporphyrinogen decarboxylase, which are associated with melanin, prawn, cytochrome P450, lutein and heme synthesis. Several genes expressed in $H$. cumingii were tested, their involvement in nacre color formation in purple and white clams at the molecular level was verified, and the pearl layer formation mechanisms of purple and white $H$. cumingii were explored through quantitative real-time PCR analysis. Results provide a theoretical basis for the direction of specific color formation of freshwater pearls.

\section{MATERIALS AND METHODS}

\section{Experimental materials}

Two-year-old purple and white $H$. cumingii mussels were used as experiment materials (Fig. 1). Difference in growth between male and female $H$. cumingii samples aged 1-2 years was not significant because their gonads have not matured yet [6]. Thus, the effect of gender on gene expression was prevented. H. cumingii samples were obtained from Zhejiang Jinhua Weiwang Breeding New Technology Co., Ltd, which has adopted a combination of families and communities to produce purple and white mussels since 2000 . H. cumingii samples caught by the company was farmed for 1 week in the laboratory. Six $H$. cumingii mussels were randomly

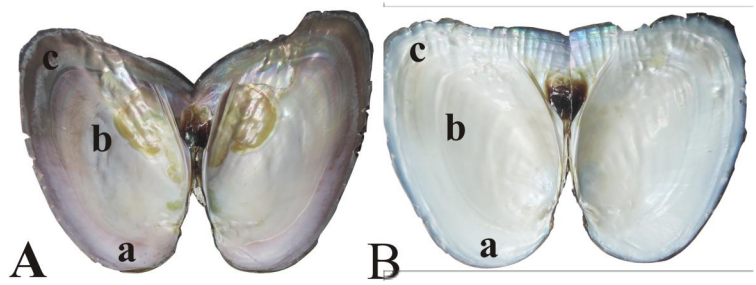

Fig. 1 Hyriopsis cumingii with purple (A) and white inner shell colors (B). a, anterior mantle pallial (aMP); $\mathrm{b}$, mantle center (MC); and c, posterior mantle pallial (pMP).

selected from each white and purple family. The samples from each selected mussel were obtained from the following: middle of the film, gill, axe, front-end velum (connected to the front-end closed shell muscle near the back-end velum), liver, kidney, pancreas and ovary back-end velum (connected to the back-end closed shell muscle and velum) near the front-end. The samples were rapidly immersed in RNA stored in fluid (Kang Wei Century), placed in a cryogenic refrigerator at $-80^{\circ} \mathrm{C}$, and set aside for further analysis.

\section{Total RNA extraction and cDNA synthesis}

The samples were placed in liquid nitrogen and ground. Total RNA was extracted with TaKaRa kit according to the manufacturer's instructions. RNA integrity was inspected through agarose electrophoresis. Nucleic acid and protein were quantitatively determined (Nanodrop 2000) and stored at $-80^{\circ} \mathrm{C}$ for subsequent use. cDNA was synthesized using PrimeScript ${ }^{\mathrm{TM}}$ RT reagent kit with gDNA Eraser (Perfect Real Time) according to the methods in the literature [7]. Reverse transcription for fluorescence quantification was performed according to the kit's instructions. Reverse-transcribed cDNA was 10 times diluted. The synthesized cDNA was stored at $-20^{\circ} \mathrm{C}$.

\section{Color correlation gene and sequence analysis}

HcTyr1, HcAst, HcCyt, HcTDO and HcUROD genes were selected from the library of the central membrane transcriptome of $H$. cumingii. The UniGene sequences of the five genes were determined using Primer Premier 5.0 Software design with PCR primer (Table S1). The PCR reaction system comprised $20 \mu 1$, which included $10 \mu 1 / 12 \times$ Ex Taq Master Mix, $0.5 \mathrm{ml}$ of each upstream and downstream primers $(10 \mu \mathrm{mol} / \mathrm{l}), 1 \mu \mathrm{l}$ of template cDNA, and double-distilled $\mathrm{H}_{2} \mathrm{O}$. The amplification conditions are as follows: 35 cycles of $94^{\circ} \mathrm{C}$ for $4 \mathrm{~min}, 94^{\circ} \mathrm{C}$ for 
$1 \mathrm{~min}, 58^{\circ} \mathrm{C}$ for $1 \mathrm{~min}, 72^{\circ} \mathrm{C}$ for $1 \mathrm{~min}$, and extension at $72{ }^{\circ} \mathrm{C}$ for $10 \mathrm{~min}$. The PCR-amplified product was subjected to $1 \%$ agarose gel electrophoresis. The product was purified with Axygen DNA kit in accordance with the kit's requirements. The amplified fragments were sent to Shanghai Bioengineering Company for bidirectional sequencing.

\section{Real-time fluorescence quantitative PCR analysis}

The sequence fragments of the five genes amplified and sequenced by PCR were designed using online primers. Primer3 Input was adapted to design the fluorescence quantitative primers for the five genes (Table S2). The primers were designed to prevent mismatches, dimers and hairpin structures. The amplified fragment size was between 170 and 80 bp, which was the same as the length of the internal gene $\beta$-actin [8]. Multiple primer pairs were also simultaneously designed, and the best pair was

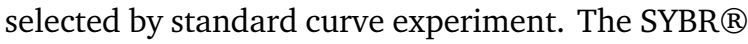
Premix Ex Taq $^{\text {тм }}$ II (Tli RNaseH Plus) kit was utilized for fluorescence-based real-time quantitative PCR (RT-qPCR) analysis. The PCR reaction system $(20 \mu \mathrm{l})$ comprised $10 \mu \mathrm{l}$ of SYBR $\AA$ Premix Ex Taq II, $0.4 \mu \mathrm{l}$ of ROX reference dye, $0.8 \mu \mathrm{l}$ of each upstream and downstream primers (10 $\mu \mathrm{mol} / \mathrm{l})$, $2 \mu \mathrm{l}$ of template cDNA, and double-distilled $\mathrm{H}_{2} \mathrm{O}$. The cDNA template was diluted into five concentrations, namely, $1 \times 5^{1}, 1 \times 5^{2}, 1 \times 5^{3}, 1 \times 5^{4}$ and $1 \times 5^{5}$, which were used to create the standard curve of the internal reference and target genes. The curves of the target and internal reference genes were prepared in triplicate. After the amplification reaction, the optimum primers and conditions were determined according to the amplification efficiency and standard curve. The amplification reaction was conducted on the ABI Step One Plus real-time fluorescence quantitative PCR instrument through the following three-step real-time PCR reaction conditions to obtain the dissolution curve: predenaturation at $95^{\circ} \mathrm{C}$ for $30 \mathrm{~s} ; 40$ cycles of $95^{\circ} \mathrm{C}$ for $5 \mathrm{~s}$ and $60^{\circ} \mathrm{C}$ for $30 \mathrm{~s}$; and $95^{\circ} \mathrm{C}$ for $15 \mathrm{~s}, 60^{\circ} \mathrm{C}$ for $1 \mathrm{~min}$, and $95^{\circ} \mathrm{C}$ for $15 \mathrm{~s}$. The relative expression levels of the five genes in each $H$. cumingii tissue was calculated using $2^{-\Delta \Delta C T}$ method [9]. Statistical analysis was conducted through one-way ANOVA in SPSS 18.0. $* p<0.05$ indicated significant difference, and $p<$ 0.01 represented extremely significant difference. A histogram was drawn using Origin8 software.

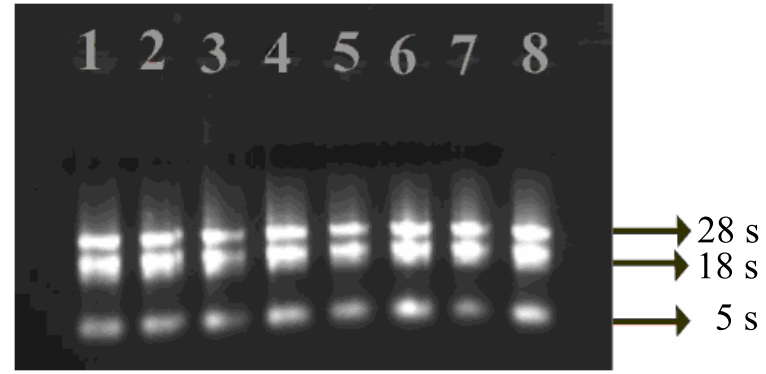

Fig. 2 Electrophoretogram of RNA of each $H$. cumingii tissue. 1, kidney; 2, gill; 3, hepatopancreas; 4, gonad; 5, foot; 6 , mantle center; 7 , aMP; and 8 , pMP.

\section{RESULTS}

\section{RNA extraction}

In the RNA electrophoretic gel diagrams of eight $H$. cumingii tissues, the extracted RNA showed three bands at 28, 18 and $5 \mathrm{~s}$ (Fig. 2). According to the result of NanoDrop 2000 ultramicrospectrophotometer, the A260/A280 value was 1.9-2.0, which indicated that the total RNA extracted had high quality and purity and can be used for subsequent experiments.

\section{Fluorescence quantitative PCR}

The $\beta$-actin gene of $H$. cumingii was used as control, and the following $H$. cumingii tissues were analyzed: central membrane, gill, axe foot, frontomarginal membrane (adjacent to the anterior obturator muscle and near the back-end), hepatopancreas, gonads, and kidneys. Reverse-transcribed cDNA that was extracted from the eight tissues of the posterior marginal membrane, which was connected to the posterior obturator muscle and adjacent to the front-end, was used as template for RT-qPCR reaction (Fig. 3). The results showed that the HcTyr1 gene was mainly expressed in the anteriorposterior marginal membrane, and its expression level in the purple mussel was significantly higher than that in the white mussel $(p<0.05)$. The $H c A s t$ gene was expressed in all $H$. cumingii tissues. The gene expression in the anterior and posterior limbic membrane $(p<0.01)$ and central membrane $(p<0.05)$ of purple mussel was significantly higher than that in white mussel. The HcCyt gene was expressed in all $H$. cumingii tissues, and the highest expression was found in hepatopancreas. The HcCyt gene expression level in the central membrane of the purple mussel was significantly higher than those in the anterior and posterior border 

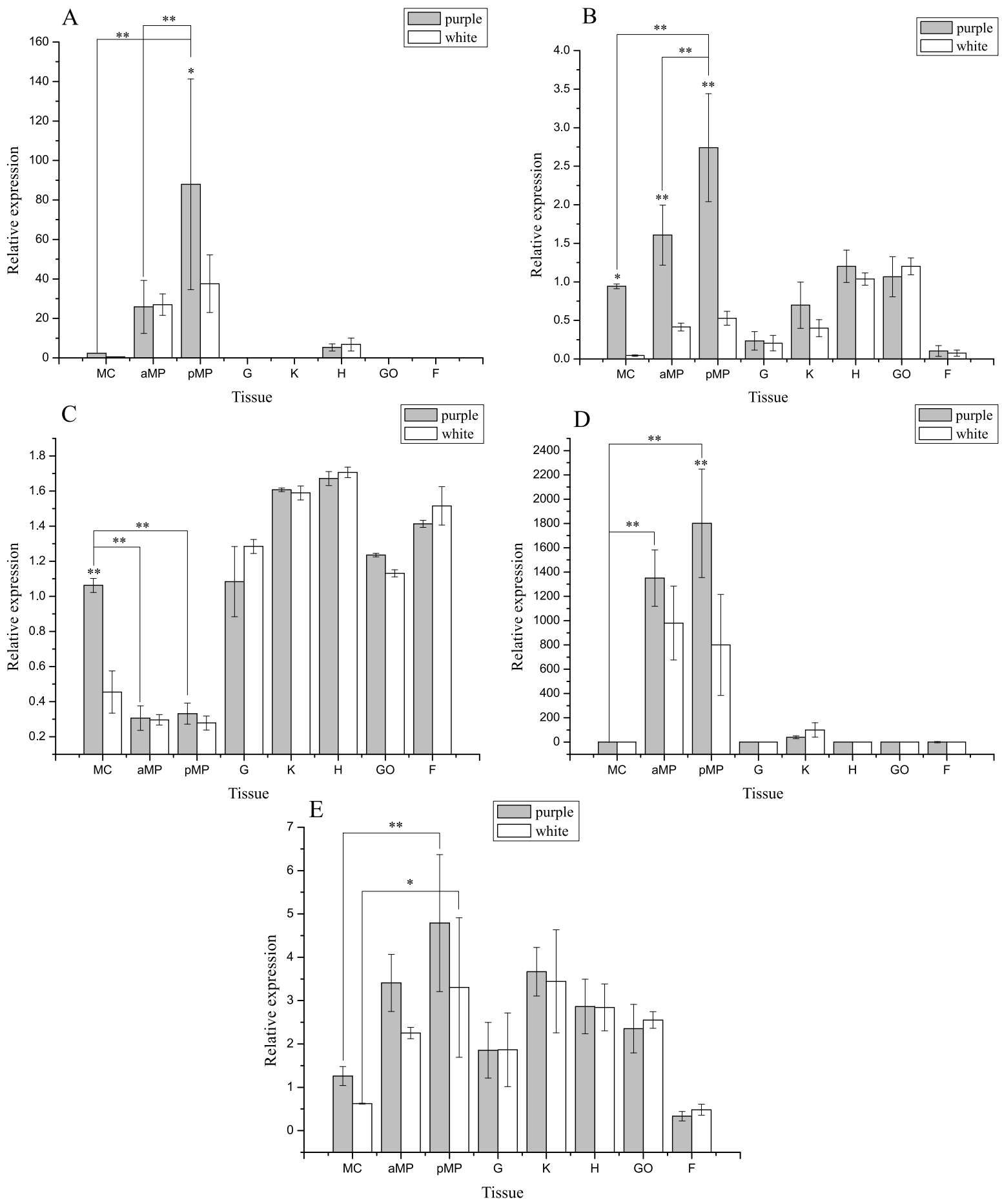

Fig. 3 Real-time quantitative PCR results of five genes in different tissues. (A) HcTyr1 gene, (B) HcAst gene, (C) HcCyt gene, (D) HcTDO gene and (E) HcUROD gene. MC, mantle center; aMP, anterior mantle pallial; pMP, posterior mantle pallial; G, gill; K, kidney; H, hepatopancreas; GO, gonad; and F, foot. * $p<0.05$ indicates statistically significant difference and $* * p<0.01$ indicate statistical extremely significant difference. 
membrane and central membrane of white mussel $(p<0.01)$. The HcTDO gene was mainly expressed in the anterior and posterior limbic membranes of $H$. cumingii. The relative expression level in the posterior marginal membrane of the purple mussel was significantly higher than that in white mussel $(p<0.01)$. The HcUROD gene expression level in the outer membrane of mussel was consistent with the outer membrane. The HcUROD gene expression level in the posterior marginal membrane was significantly higher than that in the central membrane $(p<0.01)$. The gene expression in the membrane of purple clam was higher than that in white mussel.

\section{DISCUSSION}

In this study, five genes related to the formation of the pearl layer color of $H$. cumingii were screened from the comparative transcriptional groups of the coat membrane and pearl sac of purple (purple color) and white (white pearl layer) $H$. cumingii families. The HcTyr1 gene encodes tyrosinase, which plays a role in pigment deposition, wound healing, cuticle hardening, $\mathrm{O}$ transport and innate immune processes in the organisms [10]. Tyrosinase catalyzes the hydroxylation of tyrosine into Ldopa through a series of reactions to produce essential melanin for animal eyes, skin and hair [11]. Tyrosinase can also regulate pigment synthesis in vertebrates [12]; facilitate tyrosinase activity in blood cells, egg cells and coat membrane of mollusks [13]; and form tyrosinase and shell matrix in Hupu mother shellfish. Melanin synthesis and pigment deposition occur in shell prism [14]. The TYR gene expression level significantly changed in the three typical body color fading processes of Amphilophus citrinellus. This finding indicates that the TYR gene expression level was related to the change in body color. The biosynthesis pathway of melanin in mollusks is mainly regulated by tyrosinase, which is secreted by the mantle and translocated to the shell layer [15]. Speiser [17] considered that the change in the tyrosinase expression pattern mainly affects the eye evolution of Acanthopleura granulate by altering eye pigment selection. Four tyrosinase genes were found in differentially expressed genes. These tyrosinase genes were also screened from transcriptional data and found to be similar to those of Tyr-1 and Tyr-3 in oysters [18]. Chen [19] also cloned two tyrosinase genes, namely, HcTyr and HcTyp-1, from the transcriptional library of Bai. The tyrosinase genes screened by Bai are similar to those of the Argentine squid [18]. In the present study, the HcTyr1 gene similar to the oyster Tyr-
1 gene was selected for fluorescence quantitative PCR analysis. The HcTyr1 gene was detected in $H$. cumingii central membrane, anterior marginal membrane, posterior marginal membrane, gill, kidney, hepatopancreas, gonad and axopodia tissues. The HcTyr1 gene was mainly expressed in the coat membrane and had low expression in other tissues. The $H$. cumingii outer membrane can absorb and secrete substances from the surrounding environment and is mainly involved in biomineralization. Hence, the HcTyr11 gene may be involved in shell color formation. The results of the comparative transcriptome analysis of $H$. cumingii showed that the HcTyr11 gene expression level in the central membrane of purple mussel was significantly higher than that of white mussel. The difference between the HcTyr11 gene expression level and fluorescent quantitative PCR result in the central membranes of purple and white mussels was not significant.The results varied. Luo [4] also found this problem in analyzing HcGIFLP1 gene expression in the mantle tissue of $H$. cumingii. The color of the pearl layer of the purple mussel increased from the central and the front edge membrane to the back-edge membrane (Fig. 1). The HcTyr1 gene expression level in the three tissues of the purple mussel increased with the deepening of color. No change was observed in the color of the three tissues in corresponding to the position of the pearl layer. Research showed the expression levels of the other tyrosinase gene, HcTyr in H. cumingii coating, also increased with the enhancement of the pearl layer color. Similar conditions were reported in other species. For example, the Tyr gene expression level in the hair follicles of Anas poecilorhyncha increased with the enhancement of the color of feathers. Wang [20] found that the tyrosinase gene expression level in Cyprinus carpiokoi skin with different colors (e.g., black, red, yellow and white) increased with the change in koi skin color. These studies suggested that the HcTyr1 gene plays a crucial role in pigment deposition, and its expression is related to melanin accumulation. The central membrane of $H$. cumingii is involved in pearl layer formation, and the outer membrane is involved in the formation of the pearl and prism layers. Therefore, the HcTyr1 gene may be involved in the formation of the color of the pearl and prism layers of mussel. The gene also showed correlation with the purple pearl layer color.

The analysis of differentially expressed genes in the transcriptome of $H$. cumingii revealed three genes containing the domain of the prawn bilirubin. One of these genes was selected for expression veri- 
fication. The HcAst gene encodes shrimp erythropoietin, and shrimp erythroprotease can be classified into three types on the basis of its function [21]. Meprins found in the small intestine and kidney of mammals are involved in bioactive peptide and extracellular matrix protein processing [22]. The second category includes bone morphogenetic protein1 and tolloid, which are involved in embryonic morphogenesis [23]. The third group comprises shrimplike enzymes, which participate in embryo hatching. Astacin is a digestible $\mathrm{Zn}$-dependent endopeptidase found in the crayfish Astacus astacus and prototype of the family of shrimp metalloproteinases [24]. The fluorescence quantitative results of the HcAst gene showed that its expression level in purple mussel posterior marginal membrane was significantly higher than that in the front-edge membrane. The HcAst gene expression level in the central membrane was lower than that in the front-edge membrane, but the difference was not significant. The difference in the HcAst gene expression level among the three tissues was not significant. The HcAst gene expression level in the posterior and anterior marginal membranes and also the central membrane of the purple mussel was significantly higher than that in the corresponding white mussel tissues. These results were consistent with the color phenotype of the shell pearl layer in purple and white $H$. cumingii, thereby indicating that the HcAst gene was related to the color formation of purple shell pearl layer of $H$. cumingii. The high HcAst gene expression level in the coat membrane also demonstrated that this gene was involved in shell formation. The HcAst gene was also expressed in the hepatopancreas, gonads and kidneys but low expression in the gill and axe feet. Overall, the HcAst gene may be involved in the development of the gonad reproductive system, digestion in hepatopancreas, and renal development in H. cumingii.

Cytochrome P450 (CYP450) is a single-chain protein that contains heme and widely exists in organisms [25]. CYP450 plays an important role in the degradation of exogenous substances, hormone synthesis, and $\mathrm{C}$ assimilation and acts as a structural component of organisms [26]. The metabolic pathway of cytochrome P450 is related to cytochrome metabolism. Niu [27] used transcriptome sequencing to analyze differences in gene expression in the skin of Rex rabbit with different coat colors. Eight differentially expressed genes were found in the cytochrome P450 metabolic pathway, and these genes may play roles in coat color formation. Sun [28] sequenced and analyzed differentially expressed genes in the left and right coat of scallop with asymmetric pigment patterns (the left side of the shell was reddish brown, and the right side of the shell was white). Four unknown genes and one cytochrome P450 gene were screened. According to the results of the fluorescence RT-qPCR assay, the cytochrome P450 gene expression level in the left coat membrane was significantly higher than that in right coat membrane. These finding indicated that the cytochrome P450 gene may be involved in redbrown shell color formation. In the present study, the differentially expressed cytochrome P450 gene $\mathrm{HcCyt}$ was screened from the central membrane transcriptional group of $H$. cumingii. Fluorescence quantitative analysis showed that the HcCyt gene was expressed in all $H$. cumingii tissues. It was also the least expressed in the anterior and posterior marginal membranes and highly expressed in the axon foot, gill, kidney, gonad and hepatopancreas. The gills and hatchet feet of $H$. cumingii were directly exposed to exogenous substances.The high $\mathrm{HcCyt}$ gene expression level in these tissues indicated that it may be involved in exogenous substance degradation; this finding is consistent with the results of Sun [28]. The HcCyt gene expression level was high in the hepatopancreas and kidneys which are digestive organs and excretory organs, respectively. The high expression level in the gonad tissues indicated that it may be involved in hormone synthesis. The HcCyt gene expression level in the central membrane of the purple mussel was significantly higher than that in the white clam. The gene expression in the tissue of the central membrane was significantly higher than that in the posterior marginal membrane. Given that the central membrane is mainly involved in pearl layer formation, the marginal membrane participates in pearl and prism layer formation. Hence, the HcCyt gene is related to the pearl layer color formation in purple clam.

Lutein is mainly found in protozoans, including mollusks and arthropods, and mainly produced by tryptophan via canine uric acid pathway [29]. The tryptophan dioxygenase gene HCTDO, which encodes a heme-dependent cytoplasmic enzyme, was screened from the differentially expressed genes in the transcriptome library of $\mathrm{H}$. cumingii. HcTDO contains two heme and two $\mathrm{Cu}$ atoms [30], which are essential to the catalytic activity of the corresponding enzyme; this catalytic activity is the first step of the eye flavin synthesis pathway in the liver. Tryptophan oxygenase catalyzes the uptake of tryptophan from food. The $\beta$-actin gene of $H$. cumingii 
was used as a control, and the $H$. cumingii tissues selected for analysis are as follows: central membrane, gill, axe foot, frontomarginal membrane (adjacent to the anterior obturator muscle and near the back end), hepatopancreas, gonads and kidneys. Tryptophan oxygenase is also related to eye color in insects. The tryptophan oxygenase gene is located on the $\mathrm{x}$ chromosome in Drosophila and necessary for brown pigment synthesis [31]. In the present study, the HCTDO gene had high expression level in the anterior and posterior limbic membrane of $H$. cumingii, moderate expression level in the kidney and low expression level in the other tissues. The tryptophan oxygenase encoded by the HcTDO gene of $H$. cumingii is the first enzyme in biogenic ophthalmic lutein biosynthesis. The HcTDO gene expression in the kidney of $H$. cumingii was consistent with the color of its renal tissue. The difference in the HcTDO gene expression level in the central membrane between the two mussel species was not significant. The results were inconsistent with those in the transcriptional group possibly due to the inaccuracy of the comparative transcriptome analysis. The expression level in the posterior edge membrane of purple mussel was higher than that in the front-edge membrane and increased with the deepening of the purple color. Hence, the HCTDO gene expression level was significantly correlated with the color of the purple inner shell of $H$. cumingii. This gene may also be involved in ophthalmic lutein synthesis by participating in the coat membrane; lutein is transported from the coat membrane to the shell pearl and prism layers and eventually participates in pearl color formation.

Heme is a red pigment containing $\mathrm{Fe}$ in the blood and muscle of higher animals. Approximately $70 \%$ of Fe in organisms exists in heme and can be used as an auxiliary group for many active biological macromolecules, such as cytochrome, myoglobin, hemoglobin, and peroxidase. $\mathrm{O}_{2}$ is transported and stored in the body and participates in electron transport in the respiratory chain; it is also present in all the tissues of the body [32]. In the present study, the HcUROD gene was screened from the transcription library of $H$. cumingii; this gene encodes protoporphyrin decarboxylase and is involved in heme synthesis [33]. Heme can be used as the count of catalase HcUROD gene in the kidney and hepatopancreas [34]. Catalase may be involved in the digestion function of the hepatopancreas and the excretion function of the kidneys. Heme does not solely exist in pigment form but is found in many pigment proteins; heme presents color in animals [35]. The HcUROD gene expression level was the same in the outer membrane of the clam with two colors and higher in the three parts of purple clam than that in the corresponding part of the white clam. The sequence of the HcUROD gene expression in the outer membrane of the mussel was higher than that of the white clam. Hence, the $H C U R O D$ gene may be involved in color formation of the shell prism and nacreous layer. Therefore, the role of the HcUROD gene in pearl color formation must be further studied.

\section{Appendix A. Supplementary data}

Supplementary data associated with this article can be found at http://dx.doi.org/10.2306/ scienceasia1513-1874.2020.030.

\section{REFERENCES}

1. Zhang AJ, Liu SL, Zhu JY, Gu ZM, Zhou ZM, Zhang GF, Lu KH (2016) Transcriptome analysis of the freshwater pearl mussel, Hyriopsis cumingii (Lea) using Illumina paired-end sequencing to identify genes and markers. Iran J Fish Sci 15, 479-496.

2. Zhang GF, Zhang WF, Fang AP (2016) Genetic study on the color of nacre of Hyriopsis cumingii. Chin $J$ Zool 51, 675-681.

3. Li X, Bai Z, Luo H, Liu Y, Wang G, Li J (2014) Cloning, differential tissue expression of a novel hcApo, gene, and its correlation with total carotenoid content in purple and white inner-shell color pearl mussel Hyriopsis cumingii. Gene 538, 258-265.

4. Luo HR (2015) Cloning and expression analysis of genes related to color formation of nectarine. PhD thesis, Shanghai Ocean Univ, China.

5. Chen X, Liu X, Bai Z, Zhao L, Li J (2016) HcTyr, and HcTyp-1, of Hyriopsis cumingii, novel tyrosinase and tyrosinase-related protein genes involved in nacre color formation. Comp Biochem Physiol B, Biochem Mol Biol 204, 1-8.

6. Zhao Y, Bai Z, Fu L, Liu Y, Wang G, Li J (2013) Comparison of growth and pearl production in males and females of the freshwater mussel, Hyriopsis cumingii, in China. Aquac Int 21, 1301-1310.

7. Ye YZ (2016) Molecular mechanism of lizard adaptation to hypoxia: a comparative study of sand lizards and grassland sand lizards in Tibet. PhD thesis, Hangzhou Normal Univ, China.

Ye YZ (2016) Molecular mechanism of lizard adaptation to hypoxia: a comparative study of sand lizardsandgrasslandsandlizardsinTibet[D]. Hangzhou Normal University, China.

8. Bai Z, Lin J, Ma K, Wang G, Niu D, Li J (2014) Identification of housekeeping genes suitable for gene expression analysis in the pearl mussel, Hyriopsis 
cumingii, during biomineralization. Mol Genet Genomic 289, 717-725.

9. D'Haene B, Vandesompele J, Hellemans J (2010) Accurate and objective copy number profiling using real-time quantitative PCR. Methods 50, 262-270.

10. Livak KJ, Schmittgen TD (2001) Analysis of relative gene expression data using real-time quantitative PCR and the $2^{-\triangle \triangle C T}$ method. Methods 25, 402-408.

11. Cerenius L, Lee BL, Söderhäll K (2008) The proPOsystem: pros and cons for its role in invertebrate immunity. Trends Immunol 29, 263-271.

12. Sugumaran M (2002) Comparative biochemistry of eumelanogenesis and the protective roles of phenoloxidase and melanin in insects. Pigment Cell Res 15, 2-9.

13. Hofreiter M, Schöneberg T (2010) The genetic and evolutionary basis of color variation in vertebrates. Cell Mol Life Sci 67, 2591-2603.

14. Luna-González A, Maeda-Martarnez AN, VargasAlbores F, Ascencio-Valle F, Robles-Mungaray M (2003) Phenoloxidase activity in larval and juvenile homogenates and adult plasma and hemocytes of bivalve mollusks. Fish Shellfish Immunol 15, 275-282.

15. Nagai K, Yano M, Morimoto K, Miyamoto H (2007) Tyrosinase localization in mollusk shells. Comp Biochem Physiol B, Biochem Mol Biol 146, 207-214.

16. Slominski A, Tobin DJ, Shibahara S, Wortsman $\mathrm{J}$ (2004) Melanin pigmentation in mammalian skin and its hormonal regulation. Physiol Rev 84, 1155-1228.

17. Speiser DI, DeMartini DG, Oakley TH (2014) The shell-eyes of the chiton Acanthopleura granulata (Mollusca, Polyplacophora) use pheomelanin as a screening pigment. J Nat Hist 48, 2899-2911.

18. Bai Z, Zheng H, Lin J, Wang G, Li J (2013) Comparative analysis of the transcriptome in tissues secreting purple and white nacre in the pearl mussel Hyriopsis cumingii. PLoS One 8, e53617.

19. Chen L, Shen JD, Li GQ, Fan YF, Ma JS, Lu LZ (2015) Expression and regulation analysis of Tyr, Tyrp1, and $C$-kit genes in hair follicles of different color spot bucks. $J$ Zhejiang Agric Univ 27, 729-733.

20. Wang W, Hu HX, Sun XJ, Niu CJ (2012) Sequence analysis of tyrosinase gene in koi and Its expression in different tissues of different koi carp lines. $J$ Fish Chin 36, 1658-1666.

21. Xiong X, Chen L, Li Y, Xie L, Zhang R (2006) PfALMP, a novel astacin-like metalloproteinase with cysteine arrays, is abundant in hemocytes of pearl oyster Pinctada fucata. Biochim Biophys Acta 1759, 526-534.
22. Kounnas MZ, Wolz RL, Gorbea CM, Bond JS (1991) Meprin-A and -B cell surface endopeptidases of the mouse kidney. J Biol Chem 266, 17350-17357.

23. Wozney JM, Rosen V, Celeste AJ, Mitsock LM, Whitters MJ, Kriz RW, Hewick RM, Wang EA (1988) Novel regulators of bone formation: molecular clones and activities. Science 242, 1528-1534.

24. Bode W, Gomisrüth FX, Huber R, Zwilling R, Stöcker W (1992) Structure of astacin and implications for activation of astacins and zinc-ligation of collagenases. Nature 358, 164-167.

25. Zhang LQ, Ba L, Yu SR, Ha SS (2014) Progress in cytochrome P450 2J subfamily. Prog Vet Med 8, 84-89.

26. Nelson DR (2013) A world of cytochrome P450s philosophical transactions. Proc Roy Soc B Biol Sci 368, 1-4.

27. Niu XY, Ren KL, Cao L, Li YP, Zheng JT, Feng GL, Huang SF (2016) Transcriptional genome sequencing of Rex rabbit coat-related genes. Chin Herbivore Sci 36, 1-6.

28. Sun XJ, Zhou LQ, Liu ZH (2016) Transcriptome-wide analysis reveals candidate genes responsible for the asymmetric pigment pattern in scallop Patinopecten yessoensis. Invertebr Surviv J 13, 298-308.

29. Cui KR, Ye C, Zhou W, Chai CL (2015) Silkworm body color progress. Newsl Sericult Sci 35, 21-29.

30. Efimov I, Basran J, Thackray SJ, Handa S, Mowat CG, Emma LloydRaven E (2012) Heme-containing dioxygenases. Adv Inorg Chem 64, 33-51.

31. Searles LL, Ruth RS, Pret AM, Fridell RA, Ali AJ (1990) Structure and transcription of the Drosophila melanogaster vermilion gene and several mutant alleles. Mol Cell Biol 10, 1423-1431.

32. Wang DX, Cui SY (2002) Application analysis of heme research progress. Shanghai J Prev Med 14, 219-221.

33. Laterrière M, D'Estaintot BL, Dautant A, Précigoux G, Hombrados I, De Verneuil H (1998) Expression, purification, crystallization and preliminary X-ray diffraction analysis of human uroporphyrinogen decarboxylase. Acta Cryst 54, 476-478.

34. Zhang Q, Li F, Zhang X, Dong B, Zhang J, Xie Y, Xiang J (2008) cDNA cloning, characterization and expression analysis of the antioxidant enzyme gene, catalase, of Chinese shrimp Fenneropenaeus chinensis. Fish Shellfish Immun 24, 584-591.

35. Takeuchi K, Satou Y, Yamamoto H, Satoh N (2005) A genome-wide survey of genes for enzymes involved in pigment synthesis in an ascidian, Ciona intestinalis. Zoolog Soc 22, 723-734. 


\section{Appendix A. Supplementary data}

Table S1 Primer sequences for PCR amplification.

\begin{tabular}{|c|c|c|c|c|}
\hline Number & Gene & Forward $\left(5^{\prime}-3^{\prime}\right)$ primer & Reverse $\left(5^{\prime}-3^{\prime}\right)$ primer & Size (bp) \\
\hline c28793.graph_c0 & HcTyr1 & 5'-TGTTCGCCTACAATACGG-3' & 5'-GCCCAAGTTACCTCCAAT-3' & 755 \\
\hline c57714.graph_c0 & HcAst & 5'-AGCGTTACACCTGTCTCC-3' & 5'-TTGTTTTCAACССТCСАС-3' & 384 \\
\hline c47081.graph_c0 & HcCyt & 5'-CATTTGTATCCTACTGCCTTGC-3' & 5'-TCTGGAGTGTCCCACCGTT-3' & 615 \\
\hline c59297.graph_c0 & HcTDO & 5'-GCACTTCACGATAATGGA-3' & 5'-TGGAGTCAAAGGCGGGAT-3' & 776 \\
\hline c60508.graph_c0 & HcUROD & 5'-AACATACAGGGGTCCAGG-3' & 5'-GCATCAGCACCACTTCCA-3' & 424 \\
\hline
\end{tabular}

Table S2 Primer sequences of RT-qPCR amplification.

\begin{tabular}{|c|c|c|c|}
\hline Gene & Forward $\left(5^{\prime}-3^{\prime}\right)$ primer & Reverse $\left(5^{\prime}-3^{\prime}\right)$ primer & Size (bp) \\
\hline HcTyr 1 & 5'-GGTGCATTTGGGTTCGAGATA-3' & 5'-TTTTCATGGGCTCTGCATCAG-3' & 187 \\
\hline HcAst & 5'-CCAATCGCATGCCCAATCTC-3' & 5'-CTACGATTTAAGGAGGCCGC-3' & 170 \\
\hline HcCyt & $5^{\prime}$-CTGACCCGAAATGCAAGGAAA-3' & 5'-TATTGGCTGACATGGCTTTCC-3' & 179 \\
\hline HcTDO & 5'-ATGTCCATGAGAAGGGTCAGC-3' & 5'-TGGCCGAATATCAGACAGCTA-3' & 190 \\
\hline HcUROD & 5'-CCCGAAAATGGCTTGTAACCT-3' & $5^{\prime}$-GGGAAGGGCAAATTTGTGGAA- $3^{\prime}$ & 175 \\
\hline$\beta$-actin & 5'-TCAGGGTGTGATGGTTGGTATGG-3' & 5'-AGGGGCCACACCACGGAGTTCATT-3' & 175 \\
\hline
\end{tabular}

